\title{
Total Clearance Predicted by Fraction Dose Normalized by Dose
}

National Cancer Institute

\section{Source}

National Cancer Institute. Total Clearance Predicted by Fraction Dose Normalized by

Dose. NCl Thesaurus. Code C92418.

The predicted total body clearance for extravascular administration based on the fraction of dose absorbed and divided by the dose. 